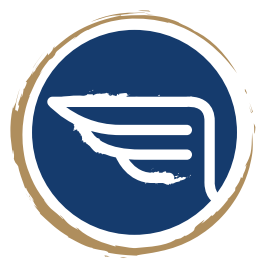

\title{
El río entre llamas
}

Brevísimas reflexiones sobre la búsqueda de la trascendencia en la poesía y su impacto en las instituciones a partir de un poema de José Gorostiza y otro de Octavio Paz.*

\section{Pablo Galindo Cruz}

Instituto de Humanidades

Universidad Panamericana, campus Aguascalientes

pgalindoc@up.edu.mx

*Este texto es uno de los dos ensayos ganadores del ler. lugar de la XI edición del Foro Universitas (2019), concurso de ensayo universitario convocado por la Universidad Panamericana, en la categoría de profesores. 


\title{
El río entre llamas
}

Autor: Pablo Galindo Cruz

Profesor investigador del Instituto de Humanidades de la

Universidad Panamericana, campus Aguascalientes.

\author{
El hombre, \\ sobre la piedra lluvia persistente \\ y río entre llamas \\ y flor que vence al huracán \\ y pájaro semejante al breve relámpago
}

Octavio Paz (de Entre la piedra y la flor).

\section{Creer en lo que no se ha visto y decir lo que no se ha escuchado.}

Las instituciones sociales no son otra cosa sino palabras: relaciones normadas de acuerdo con lo que, a lo largo de los años, hemos ido descubriendo como bueno. Tales palabras pueden estar efectivamente escritas, en los códigos jurídicos que dan lugar a las instituciones públicas, o pueden ser preceptos morales universalmente válidos.

Por ello, los escritores, y los poetas, juegan un rol fundamental en el desarrollo de las instituciones. No porque sean citados como referente en el momento de formular postulados positivos o morales, tampoco porque el grueso de una población esté familiarizado con su obra, ni siquiera porque sea tomado en cuenta por los líderes políticos, cuya cultura literaria suele ser paupérrima.

Su importancia radica en que, sepámoslo o no, hablamos con el lenguaje que nos han heredado, pensamos sobre el mundo que ellos han descifrado con sus palabras y somos en quienes, para bien o para mal, se cumplen sus vaticinios.

¿Puede esto afirmarse en un país como México, que aparece en el lugar 107 de 108 países que contabiliza la UNESCO en su índice de lectura?' ${ }^{1}$ espondo que sí: La literatura de un país constituye parte fundamental de su carácter nacional. No en vano, Octavio Paz, en el discurso que pronunció en 1990 al recibir el Premio Nobel de Literatura, presentó un

1. Cfr. «México, en el lugar 107 de 108 en índice de lectura: UNESCO», Nidia Rodríguez, acceso el 19 de marzo de 2019, http://www.udgvirtual.udg.mx/noticia/mexico-en-el-lugar-107-de-108-en-indice-delectura-unesco 
análisis del carácter cultural de Latinoamérica a partir del surgimiento de una literatura propia, que vimos a aparecer en la segunda mitad del siglo pasado².

Quienes no habitan las letras de su cultura viven en ningunaparte, como exiliados conformes con su propio aislamiento. Sólo puede habitarse el mundo cuando se habita en el lenguaje.

No pretendo afirmar, desde luego, que cada mexicano deba ser experto la literatura nacional, pero sí que no puede ser ajeno al modo en que ésta ha conformado una cosmovisión propia, unos objetos de culto y un sentido de trascendencia.

La calidad de las instituciones públicas depende en buena medida de la calidad del discurso, la cual se hace posible gracias a nuevas formas de lenguaje. La práctica de la poesía resulta así, natural y necesaria en toda comunidad política.

Nuestro país tiene un amplísimo bagaje literario que abarca todos los géneros, pero es particularmente claro en la poesía. Para muestra está el célebre volumen de Poesía en movimiento, antología con selección y notas de Octavio Paz, Alí Chumacero, José Emilio Pacheco y Homero Aridjis que reúne a más de 40 poetas, todos los suficientemente canónicos como para figurar en dicha selección.

El presente texto parte de la aceptación de la importancia del discurso literario, particularmente el poético, para la comunidad política, para después seleccionar, de entre el vasto universo de poetas mexicanos, a José Gorostiza (1901-1973) y a Octavio Paz (1914-1998). Tal selección se debe a dos motivos:

Primero, que tanto Gorostiza como Paz son autores de lo que bien podría conformar un tríptico de poemas filosóficos de largo aliento conformado por el Primero sueño (1692), de Sor Juana, Muerte sin fin (1939) de Gorostiza, y Piedra de sol (1957) de Paz.

Aunque por motivos de tiempo y espacio omitiremos a Sor Juana de este breve ensayo (lo cual también resulta conveniente para centrarnos en autores contemporáneos),

2. Cfr. Octavio Paz. «La búsqueda del presente» La búsqueda del presente. 1991, Premio Nobel, acceso al 19 de marzo de 2019, https://www.nobelprize.org/prizes/literature/1990/paz/25350-octavio-paz-nobellecture-1990/. 
subrayamos el vínculo que Primero sueño tiene con ambos poetas y que echa raíces en las Soledades de Góngora, como lo recuerda Frank Dauster ${ }^{3}$.

La segunda por razón la que hemos escogido estos dos autores es por el intento de investigar, a partir del lenguaje poético, sobre aquello que no puede decirse de ninguna otra manera sino con el excedente de sentido que representa la metáfora.

Ambos poetas, Gorostiza y Paz, buscan, a través del lenguaje, nombrar lo no nombrado y acceder a una sustancia poética, algo que, en términos llanos podríamos entender como el significado puro de un significante transparente logrado por la forma literaria adecuada. El tema que nos convoca es la relación entre la fe y la razón, y el modo en que éstas se concilian en la vida institucional. Aunque cualquier pretexto es provechoso para hablar de literatura, en esta ocasión me parece que se encuentra plenamente justificado:

Ya decía Aristóteles en la Ética que el arte es un modo de ser productivo acompañado de razón verdadera ${ }^{4}$, un sociedad que dice mal, o dice poco, nunca podrá ser una sociedad institucionalmente fuerte.

Y en el corazón de la labor literaria siempre aparece la idea de la trascendencia. La fe consiste en creer en aquello que no se ha visto, la poesía en decir lo que no se ha escuchado.

\section{Dos momentos culmen.}

El tiempo y las pretensiones de este ensayo no permitirán un análisis exhaustivo, ni siquiera detallado, de los poemas que, para los efectos de nuestra argumentación se seleccionaron: uno de José Gorostiza, Muerte sin fin, y otro de Octavio Paz: Piedra de sol. Dice Octavio Paz, en la introducción a la edición de 1979 de su Obra Poética, que todo poema es un borrador de un poema que nunca escribiremos. Parafraseándolo podemos decir que todo ensayo es siempre introductorio, siempre el bosquejo de un texto mayor que nunca escribiremos.

En estas breves líneas no buscamos, desde luego, el rigor de la crítica literaria ni la profundidad del artículo de investigación: nuestro propósito es delinear las ideas suficientes

3. Cftr. Frank Dauster. The double strand. Five contemporary mexican poets (The University Press of Kentucky, 1987).

4. Cfr. Et. Nic. IV, 4, 1140a 15 
que permitan detonar el interés por la lectura de las obras presentadas y comprobar la tesis de que la reflexión literaria permite tanto fortalecer los vínculos institucionales (racionales) de una comunidad como reflexionar en torno a la tensión fe-razón.

\section{Muerte sin fin (José Gorostiza, 1939)}

El sentido trascendente del poema se anuncia desde los epígrafes seleccionados por Gorostiza: tres fragmentos del libro de los Proverbios que hacen referencia, respectivamente, a la inteligencia, al orden y a la muerte ${ }^{5}$. Tales temáticas merecen, sin duda, una investigación que el poeta se dispone a realizar: la palabra divina como preámbulo del intento de ascender hacia el misterio desde el barro de la palabra humana.
Lleno de mí, sitiado en mi epidermis
por un dios inasible que me ahoga
mentido acaso
por su radiante atmósfera de luces
que oculta mi conciencia derramada.

Los primeros versos del poema enfrentan al lector con la angustia de aquel que en la búsqueda de lo divino reconoce que la conciencia queda excedida ${ }^{6}$ : la verdad aparece siempre deslumbrante: del mismo modo en que los sentidos se ven desbordados ante una luz demasiado brillante, la razón se ve derramada ante la búsqueda de la trascendencia.

Sin embargo, el poeta advierte que en algún modo la inteligencia debe ser capaz de contener el misterio:

No obstante- oh paradoja-, constreñida

por el rigor del vaso que la aclara, el agua toma forma.

5. Proverbios, $8,14-8,30-8,36$.

6. En este punto conviene advertir que las interpretaciones que puedan hacerse a este tipo de obras son siempre un tanto arbitrarias: el pleno cumplimiento de la función poética exige que aquello que se escribe no pueda decirse de ninguna otra forma. En este tipo de poesía, a la que podríamos llamar "pura", la palabra no cumple una función ornamental sino plenamente creativa. Si el poeta hubiera podido decir lo que aparece en el poema de cualquier otra manera, la obra ni siquiera hubiera sido necesaria. Sin embargo, intentaremos no una interpretación, sino un comentario, desde la enorme subjetividad que ello implica. 
Los siguientes versos refieren esa desesperación por no lograr un conocimiento de Dios, y confunde, al menos en apariencia, si es la inteligencia la que, como un recipiente, moldea la idea de lo divino, o si lo es lo divino lo que moldea el alma humana. Sin embargo, el poeta parece experimentar al percibir que la razón no se basta por sí sola:

\author{
Tal vez esa oquedad que nos estrecha \\ en islas de monólogos sin eco, \\ aunque se llama Dios, \\ no sea sino un vaso \\ que nos amolda el alma perdidiza.
}

El poeta reflexiona en la relación que existe entre la inteligencia y su objeto: ¡oh inteligencia, soledad en llamas/ que todo lo concibe sin crearlo. ¿Es la inteligencia la que crea la palabra, o apenas la descubre?, ¿hay algo anterior a ésta?, ¿qué se esconde detrás del sonido, aparentemente arbitrario, que se transforma en decir?

Tal fue una preocupación reiterada en la obra de Gorostiza, como consta también en los poemas inconclusos, disponibles al gran público gracias a la edición que en el Fondo de Cultura Económica realizó Guillermo Sheridan.

En su esfuerzo, el poeta no sólo responde a su propia necesidad de dar cauce a sus inquietudes intelectuales, sino que enriquece el panorama de la literatura mexicana, y así del carácter nacional, y contribuye a construir los cimientos comunes de palabras sobre las que ha de edificarse nuestra cultura. Y nuestras instituciones.

Piedra de sol (Octavio Paz, 1957).

Es probable que calificar a Octavio Paz como un poeta agnóstico sea una clasificación un tanto simplona. Es cierto que no abrazó el credo cristiano, por lo menos no públicamente, en ningún momento de su vida. Sin embargo, la reflexión en torno a la idea de Dios es constante a lo largo de su obra.

En Libertad bajo palabra, su primer libro de poesía, publicado en 1960, El ausente ha sido uno de los poemas más difundidos en tanto se considera una clara profesión de agnosticismo. 
Es notable que el poeta haya dado un lugar capital a la reflexión en torno a Dios que, en algunos momentos, da la impresión de ser angustiante: Dios insaciable que mi insomnio alimenta, reza el primer verso, y más adelante da algunos pormenores de esta búsqueda.

Te he buscado, te busco, en la árida vigilia, escarabajo

de la razón giratoria;

en los sueños henchidos de presagios equívocos

$y$ en los torrentes negros que el delirio desata.

Piedra de sol, publicado en 1957 (siete años después de El laberinto de la soledad), es, de acuerdo con Armando González Torres, el poema de unidad y largo aliento que incorpora definitivamente a Paz en la genealogía de los grandes escritores que él mismo venía delineando en sus ensayos, es el texto que lo sitúa de una vez como un poeta moderno y universal ${ }^{7}$.

Su temática, como todo buen texto poético, no puede reducirse a un argumento o narración. Pero sí podemos seleccionar un par de fragmentos que ilustren es tensión ferazón de la que hemos hablado en este breve ensayo, y que sean prueba del modo en que dicha reflexión quedó permanentemente instalada en algunas de las páginas más brillantes de la literatura mexicana contemporánea:

el mundo se despoja de sus máscaras

y en su centro, vibrante transparencia,

lo que llamamos Dios, el ser sin nombre,

se contempla en la nada, el ser sin rostro

emerge de sí mismo, sol de soles,

plenitud de presencias y de nombres;

Es necesario quebrar el lenguaje en la búsqueda de la sustancia poética a la que hacía referencia Gorostiza. El juego de opuestos, tan usual en la literatura culterana (hasta donde podríamos trazar las raíces que dan origen a este texto), permite dotar a la palabra de un nuevo sentido.

7. Cfr. Armando González Torres, Piedra de sol (comentario a) en el suplemento Guardajugas de La Jornada Aguascalientes, 31 de marzo de 2014. 
Si tratáramos de dar una interpretación, siempre parcial y un tanto arbitraria, del pasaje anterior, podríamos atrevernos a decir que Dios es el ser sin nombre porque es el ser mismo: La misma tradición judeocristiana da cuenta de esta dificultad para nombrar al autor de todas las cosas, ese Dios, antes desconocido, al que se refirió San Pablo cuando predicó a los atenienses.

Dios emerge de sí mismo, es la causa de causas, el sol de soles /la luz de luz/, que es sólo presencia. Que es plenitud de presencias y de nombres.

Se debe reconocer que la interpretación que hacemos es fragmentaria en tanto que no toma en cuenta la totalidad del poema sino sólo una parte. Sin embargo, en la buena poesía, cada parte es también un todo.

Más allá de interpretaciones que puedan resultar facilonas y cursis, estamos en condiciones de aceptar que la buena literatura no puede más que buscar contemplar el misterio (quien habla solo espera hablar a Dios un día, decía Machado), y que la búsqueda de la trascendencia o, al menos, el atisbo de ella, está claramente presente en el carácter cultural mexicano.

\section{Un edificio de palabras.}

Julio Hubard, biógrafo y confeso admirador de Paz, escribió alguna vez, al reseñar un libro de Mogens Herman Hansen, que la democracia no es una estructura de piedras sino de palabras ${ }^{8}$.

Todas nuestras instituciones lo son. En estas brevísimas líneas, que quedan siempre como la promesa de que algún día serán continuadas, hemos tratado de demostrar que de la calidad del lenguaje es fundamental para el desarrollo de las instituciones, pues éstas, no están construidas sino de palabras.

Ethel Junco, querida maestra de nuestra Universidad, ha hablado con claridad al respecto: “Atenas es el lugar del apogeo de la palabra y ésta está al servicio de la cultura cívica: la

8. Julio Hubard el 09 de febrero de 2013, Cómo se pierden las democracias, Letras Libres, acceso al 25 de marzo de 2019, https://www.letraslibres.com/mexico/como-se-pierden-las-democracias. 
asamblea y los festivales dramáticos son ejemplo del alcance de logos aplicado a todos los asuntos, políticos y jurídicos o religiosos y morales.".

En el centro mismo de este lenguaje se encuentra la poesía, y en el corazón de ella la búsqueda incesante, insomne, de la trascendencia. Es Dios quien se da a conocer a quién Él mismo le confiere el don de la fe, pero en la naturaleza misma del hombre, en lo más nuclear, que es el lenguaje, permanece la inquietud ante el misterio.

El esfuerzo de Gorostiza pone de manifiesto que la palabra puede alzarse hacia sentidos que la trasciendan, elevando así al hombre mismo hacia las cumbres que le son propias. Entendida así, la literatura deja de ser un mero divertimento o ejercicio intelectual para convertirse en vínculo, tanto entre los hombres como hacia el misterio.

Por su parte, la obra de Octavio Paz, aunque no da razón del encuentro con la divinidad, sí manifiesta la incesante lucha de la razón por conocerla. Al hacerlo, fija la inquietud en el edificio de la literatura mexicana.

La obra de Gorostiza y Paz, y la de muchos otros poetas que han construido el edificio de palabras de nuestra cultura, ha sido, con mayor o menor eficacia, manifestación de un deseo que (nosotros sabemos) sólo podrá satisfacerse ante la contemplación de lo divino.

\section{Referencias bibliográficas:}

Aristóteles, Ética Nicomáquea, Trad. de Julio Pallí Bonet. Gredos (Barcelona, 2007).

Frank Dauster, The double strand. Five contemporary mexican poet (The University Press of Kentucky, 1987).

Gustavo Esparza (ed.), Pedagogía y ética (Texere- Universidad Panamericana, Campus Aguascalientes, 2019).

Armando González Torres, Piedra de sol (comentario a) en el suplemento Guardajugas de La Jornada Aguascalientes, 31 de marzo de 2014.

9. Ethel Junco, «La Apología de Sócrates como texto preliminar para la ética de las profesiones », Pedagogía y ética (Texere- Universidad Panamericana, Campus Aguascalientes, 2019). 
José Gorostiza, Poesía completa. Nota y recopilación de Guillermo Sheridan (México: FCE. México, 1996).

Julio Hubard el 09 de febrero de 2013, Cómo se pierden las democracias, Letras Libres, acceso al 25 de marzo de 2019, https://www.letraslibres.com/mexico/como-sepierden-las-democracias.

Octavio Paz. «La búsqueda del presente» La búsqueda del presente. 1991, Premio Nobel, acceso al 19 de marzo de 2019, https: / www.nobelprize.org/prizes/ literature/1990/paz/25350-octavio-paz-nobel-lecture-1990/.

Octavio Paz, Obra poética (1935-1988) (Barcelona: Seix Barral, 1990). 